\title{
2006-2040: MEETING THE LEARNING STYLES OF BIOMEDICAL ENGINEERS IN A MAINSTREAM GENETICS COURSE: A BIOLOGIST'S PERSPECTIVE
}

\section{Peter Coppinger, Rose-Hulman Institute of Technology}

J. Peter Coppinger is an Assistant Professor of Applied Biology and Biomedical Engineering at the Rose-Hulman Institute of Technology. His teaching portfolio includes courses in genetics and molecular biology, microbial biotechnology, and molecular pathogenesis. He received his $\mathrm{PhD}$ in molecular plant biology at UC Berkeley in 2005, and conducts research in plant-pathogen interactions. Peter Coppinger may be reached at coppinge@rose-hulman.edu.

\section{Shannon Sexton, Rose-Hulman Institute of Technology}

Shannon M. Sexton is currently the Director of Assessment at Rose-Hulman Institute of Technology where she designs and implements assessment activities for both small and large scale projects. She has presented her work at national psychology and assessment conferences and has published in the areas of political and social psychology. Shannon holds an MA degree in General Experimental Psychology. 


\section{Meeting the learning styles of biomedical engineers in a mainstream genetics course: a biologist's perspective}

\section{Introduction}

A primary goal of undergraduate biomedical engineering programs is to graduate scientifically literate students who are well trained in biology, mathematics, and the physical and engineering sciences. Given this demanding course load, it is not surprising that a full genetics course is uncommon in biomedical engineering curriculum. Exposure to advanced topics in genetics, however, is important for a comprehensive understanding of biology. In the biotechnological age, the ability of students to address questions related to health, medicine, and disease requires a thorough understanding of genomics, bioinformatics, and recombinant DNA technology. A full course of genetics can therefore enrich the biology sequence of biomedical engineering curricula, and encourage students to approach problems from a biological perspective.

Introductory biology courses often serve as the only source of genetics for engineering students. In other cases, biomedical engineering students enroll in condensed or half-courses in molecular biology and genetics tailored specifically for engineering students. While this may be feasible at a large university, faculty and resource constraints at small colleges often necessitate that biomedical engineering students and traditional biology students enroll concurrently in the same courses. For small undergraduate institutions, enrolling biomedical engineering students in a "mainstream" genetics course (required for traditional biology majors) is a simple way to integrate a full course of genetic analysis into a biomedical engineering curriculum.

However, enrolling biomedical engineering students in an upper-level genetics course typically designed for traditional biology students raises several questions that should be addressed. Do learning styles of biomedical engineering students differ from traditional biology students, and do these learning preferences influence the performance of engineering students in an upperlevel biology course? For example, if engineering students prefer a "sequential" approach to learning while traditional biology students prefer a "global" approach, the instructor may have a difficult time effectively teaching both groups of students simultaneously.

Rose-Hulman Institute of Technology, a small undergraduate institution, requires biomedical engineering students to take an upper-level genetics course as part of the standard curriculum. This study evaluates the performance of biomedical engineering students enrolled in an upperlevel genetics course designed for traditional biology students. This study also assesses how exposure to advanced topics in genetics, including Mendelian and molecular genetics, bioinformatics, and recombinant DNA technology affects a biomedical engineering student's ability to approach problems from a biological perspective, and influences their perceptions on how genetic analysis can be used to solve engineering problems. Finally, this study addresses the alleged obstacles in offering a full genetics course to biomedical engineering students, particularly with regards to perceived differences in learning styles of biomedical engineering students and traditional biology students, and appropriate placement of such a course in the biomedical engineering curriculum. 


\section{Course structure, objectives, and demographics}

The Department of Applied Biology and Biomedical Engineering (ABBE) at Rose-Hulman offers "Mendelian and Molecular Genetics" as a required upper-level biology course for biomedical engineers. Taught by biologists, this course contains a mixture of biology and engineering students. Biology majors typically enroll in the course during the fall of the sophomore year, directly following the year-long sequence of introductory biology courses. Due to a heavy sophomore curriculum in engineering and mathematics, biomedical engineering students typically enroll during the fall of the junior year, and are therefore more than a year removed from core biology courses.

During the Fall Quarter 2005, "Mendelian and Molecular Genetics" exhibited the following demographics, as indicated by major, gender, and year:

Table 1: Demographic Information by Major
\begin{tabular}{|l|c|c|}
\hline & Biology & $\begin{array}{c}\text { Biomedical } \\
\text { Engineering }\end{array}$ \\
\hline \multicolumn{1}{|c|}{ Year } & & \\
\hline Sophomore & 5 & 3 \\
\hline Junior & 4 & 27 \\
\hline Senior & 1 & 0 \\
\hline & & \\
\hline Gender & & \\
\hline Male & 2 & 20 \\
\hline Female & 8 & 10 \\
\hline & & \\
\hline
\end{tabular}

"Mendelian and Molecular Genetics" focuses on the concepts of classical and molecular genetics using a hypothesis-driven problem solving approach. This course is designed to explore current topics in genetic research, and discuss genetic and molecular tools used to investigate biological problems. The goal of this course is to provide students with a solid understanding of the biochemical link between genotype and phenotype, as well as the skills and knowledge to approach biological questions from a genetic perspective, including the use of bioinformatics, genomics, and recombinant DNA technology.

\section{Survey design and data collection process}

During the summer of 2005, the Office of Institutional Research, Planning, and Assessment (IRPA) at the Rose-Hulman Institute of Technology, in conjunction with the course instructor created a confidential course survey for the "Mendelian and Molecular Genetics" course. All surveys were administered online during the last week of the fall quarter and the first week of the winter quarter. The course survey contained questions regarding the relevance of the course to the student's major, course placement, problem solving skills, and future plans. Specifically, 
students were asked (on a scale of 1 to 4) whether they strongly disagreed (1), disagreed (2), agreed (3), or strongly agreed (4) with the following statements:

1. "I clearly see the relevance of this course to my major"

2. "The location of this course in my course sequence is appropriate"

3. "This course required me to utilize the problem solving skills I learned in other courses to solve biological problems"

4. "This course provided me new approaches to solving biological problems"

5. "This course positively influenced my perceptions about the importance of genetics in approaching biological problems"

For each question, students were encouraged to provide additional comments. Students were also asked questions pertaining to future career plans, and whether or not the genetics course influenced these plans.

\section{Survey results}

An ANOVA was run to test for differences between the three majors; biology, biomedical engineering, and other. The other category was made of students majoring in engineering or science fields other than biology or biomedical engineering. There were no statistically significant differences at the $\mathrm{p}<.05$ value between biology, biomedical engineering, or other students on survey results or grades. Therefore, the data reported here will be central tendencies and frequencies only and will focus only on applied biology and biomedical engineering students as this is the sample of interest.

It is important to note the difference in $\mathrm{n}$ size between the groups. It is possible that there are differences between the groups, but given the small sample size, there is insufficient statistical power to find them with only ten biology students. To fully investigate differences between the groups, more data will need to be collected in subsequent quarters for analysis.

\section{Course performance and perceptions}

Biology majors earned slightly higher course grades then biomedical engineering majors, although the differences are not significant (Table 2). Biology majors generally rated the relevance of this course to their major, appropriateness of course placement in their academic sequence, gaining a new approach to solving biological problems, and the importance of genetics higher than biomedical engineering majors. However, biomedical engineering majors rated their need to use problems solving skills learned in other courses higher than biology students. 


Table 2: Mean Rating by Major (1 = strongly disagree, 2 = disagre
\begin{tabular}{|l|c|c|} 
3 = agree, 4 = strongly agree) \\
\cline { 2 - 3 } & Biology & $\begin{array}{c}\text { Biomedical } \\
\text { Engineering }\end{array}$ \\
\hline Grade (on 4pt scale) & 3.55 & 3.45 \\
\hline $\begin{array}{l}\text { "I clearly see the relevance of this } \\
\text { course to my major" }\end{array}$ & 3.63 & 3.07 \\
\hline $\begin{array}{l}\text { "The location of this course in my } \\
\text { course sequence is appropriate" }\end{array}$ & 3.63 & 3.14 \\
\hline $\begin{array}{l}\text { "This course required me to utilize } \\
\text { the problem solving skills I learned } \\
\text { in other courses to solve biological } \\
\text { problems" }\end{array}$ & 3.00 & 3.15 \\
\hline $\begin{array}{l}\text { "This course provided me new } \\
\text { approaches to solving biological } \\
\text { problems" }\end{array}$ & 3.63 & 3.21 \\
\hline $\begin{array}{l}\text { "This course positively influenced } \\
\text { my perceptions about the } \\
\text { importance of genetics in } \\
\text { approaching biological problems" }\end{array}$ & 3.88 & 3.39 \\
\hline
\end{tabular}

Most biomedical engineering students found the placement of this course in the curriculum appropriate (Table 2). However, several biomedical engineering students reported that they would have preferred that this course occur earlier in the curriculum, as evidenced by the following selected comments:

"[Genetics] should be taken closer to when biology is required in the curriculum."

"[Genetics] might be beneficial to be after biology, so our minds are still on that track..."

"I think that [genetics] would have been more beneficial if it was [sic] squeezed into the sophomore year."

"[Genetics] would go better right after taking biology where most of this micro stuff is still fresh in our minds rather than taking a year off from all biology material..."

Biomedical engineering majors also reported that this course provided new approaches to solving biological problems. Many biomedical engineering students commented that this course helped them realize the significance of genetics in the field of health and medicine, and how genetic analysis is a powerful tool for investigating the organization and function of life (see comments below): 
“...this course helped me realize what types of research can be done on a genetic level to increase the quality of life for people."

“...I got a really strong emphasis on the general flow of biological systems. I feel like I now have several interrelated perspectives from which to attack biological problems. "

"This course gave me a greater sense of the transmission of biological diseases."

"This course helped me realize that there are so many different ways that genetics can be used to deal with biological problems."

"As biomedical engineers, we are responsible for solving problems related to biology with an engineering perspective. To be complete in our analysis we have to understand the genetics behind a certain biological problem."

The greatest apparent difference between biology and biomedical engineering students was in response to statement \#1, "I clearly see the relevance of this course to my major." While biology majors tended to "strongly agree" with this statement, most biomedical engineering students only "agreed." Although many biomedical engineering students reported that this course inspired an appreciation for genetic analysis (see above), several students commented that they were unsure of how this course relates to the biomedical engineering curriculum:

"I don't know if I will even use this material however I think it is important for biomedical engineers to have a general understanding of genetics."

"I understand the importance in being knowledgeable in [genetics], but I don't see the relevance to biomechanics."

"I'm not sure as to how much biomedical engineers need to know about genetics and biochemistry in general."

"This course has little to do with biomechanics... and not a whole lot to do with biomaterials. Whatever information was intended to apply to these topics was not clearly connected. I would have loved to have seen how I could apply genetics to biomaterials problems."

Perhaps not surprisingly, these sentiments are also consistent with the course's impact on postgraduation plans (see below), in which the majority of biomedical engineering students reported that the genetic course had little or no influence on future career plans.

\section{Future career plans}

The majority of biology students plan on enrolling in a biology $\mathrm{PhD}$ program following graduation (Table 3). Other future plans of biology students include biology master's program or medical school. For most biology students, this course reinforced or enhanced their desires to pursue a higher degree in biology. 
Table 3: Percentage of Student Responses by Major

\begin{tabular}{|l|c|c|}
\hline & Biology & $\begin{array}{c}\text { Biomedical } \\
\text { Engineering }\end{array}$ \\
\hline Graduation Plans & $\mathrm{N}=10$ & $\mathrm{~N}=30$ \\
\hline Biology MA/MS & $10 \%$ & $0 \%$ \\
\hline Biology PhD & $40 \%$ & $3.3 \%$ \\
\hline $\begin{array}{l}\text { Biomedical } \\
\text { Engineering MA/MS }\end{array}$ & $0 \%$ & $0 \%$ \\
\hline $\begin{array}{l}\text { Biomedical } \\
\text { Engineering PhD }\end{array}$ & $0 \%$ & $6.7 \%$ \\
\hline Medical School & $20 \%$ & $13.3 \%$ \\
\hline Job Market & $0 \%$ & $23.3 \%$ \\
\hline Undecided & $0 \%$ & $26.7 \%$ \\
\hline Other & & $20 \%$ \\
\hline & $40 \%$ & \\
\hline Influence & $20 \%$ & $10 \%$ \\
\hline Reinforced & $10 \%$ & $13.3 \%$ \\
\hline Enhanced & $0 \%$ & $40 \%$ \\
\hline New Desire & $10 \%$ & $16.7 \%$ \\
\hline No Impact & & \\
\hline Other & & \\
\hline & & \\
\hline & & \\
\hline
\end{tabular}

In contrast, the majority of biomedical engineering students are undecided as to their future plans (Table 3). Others reported planning on entering the job market, enrolling in medical school, a biomedical engineering PhD program, or a biology PhD program. For the slight majority of biomedical engineering students, this course had little to no impact on future career aspirations. For other biomedical engineering students, however, this course inspired interest in genetic research, as evidenced by selected student comments below:

"...it's good to know how much genetics will contribute to the different diseases, etc. as it will pertain to my future patients as well as much knowledge of medicine. I believe that this class will prove extremely useful in bringing in an outside thought process for problem-solving in the medical field."

"This course caused me to consider seriously doing a PhD program in molecular biology."

"[Recombinant] DNA technology has always been of interest to me, so this course helped me to understand more about it. I may possibly want to enter the genetic engineering field." 
"I am considering a field in genetics now, in which I can also use my Biomaterials major. I am debating whether to enter the job market or continue my education in genetics."

"Before this course, I planned to major in biomedical engineering and minor in applied biology. Taking this course made me realize that I would like to pursue genetic engineering and biotechnology as a career, and caused me to adjust both my major and my post-graduation plans."

\section{Index of learning styles (ILS) distribution}

The Index of Learning Styles is a survey used to assess a student's learning profile (including learning style preferences) in four general categories listed below with a brief description ${ }^{1}$ :

1. Active/reflective learning: Does the student prefer to learn something by actually "doing" it (active learner), or do they prefer to think about it quietly (reflective learner)?

2. Sensing/intuitive learning: Does the student prefer using facts and wellestablished methods for solving problems (sensing), or do they prefer learning abstractions and general concepts (intuitive)?

3. Visual/verbal learning: Does the student learn best using diagrams, pictures, charts, etc. (visual), or by reading the textbook and listening to lectures (verbal)?

4. Sequential/global learning: Does the student learn best when the information is presented in logical steps (sequential learner), or by grasping the "big picture" first and learning the small details later (global learner).

Below is the distribution of ILS scores for biology and biomedical engineering students. A score of 1-3 indicates balance on the two dimensions of each scale while a score of 5-7 indicates moderate preference for one dimension of a scale. A score of 9-11 indicates a strong preference for one dimension of a scale. When a moderate preference exists, students will learn more easily in a teaching environment favoring that dimension. When a strong preference exists, students may have difficulty learning in an environment that does not support their preference.

According to the distributions for students enrolled in this course, it appears that biology and biomedical engineering students are well balanced on the active/reflective, sensing/intuitive, and sequential/global scale, however both groups of students seem to have a preference for the visual dimension of the visual/verbal scale. 


\section{Distribution of ILS for Biology Students}

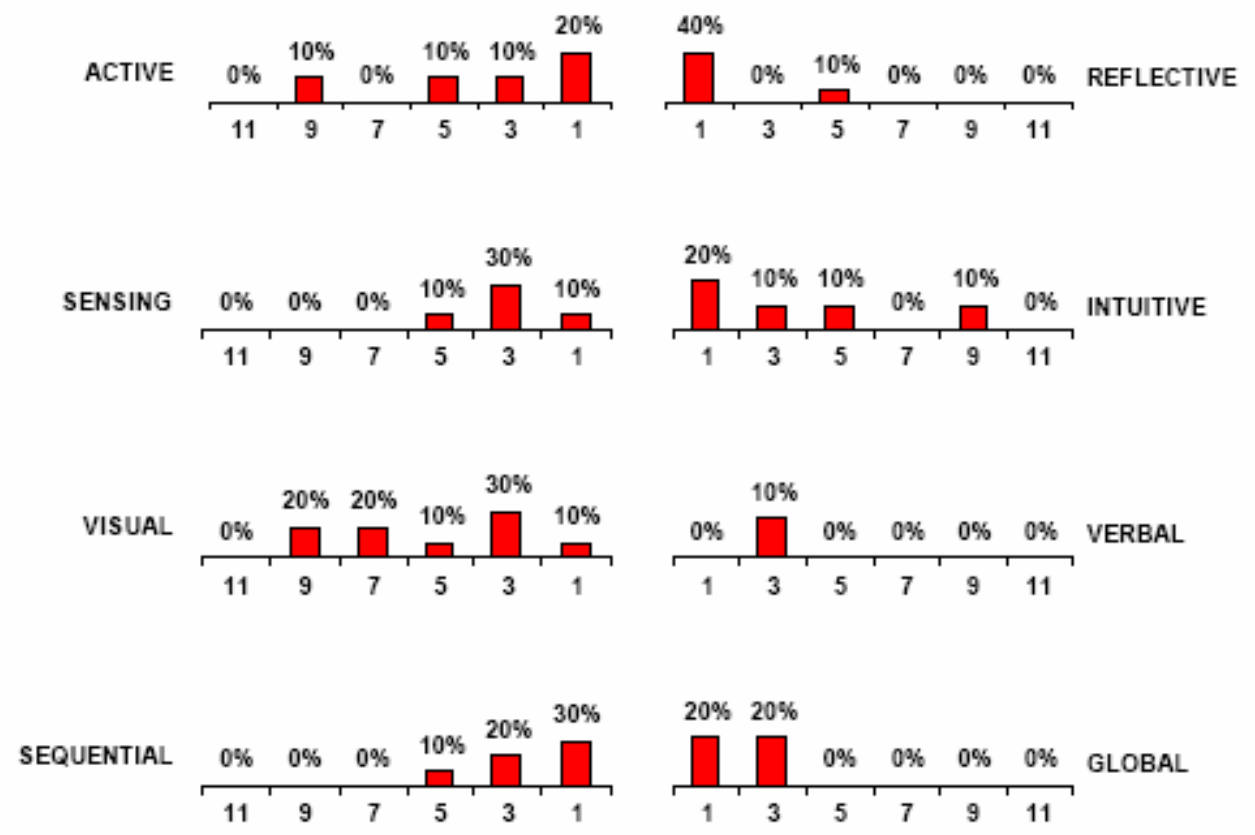

Distribution of ILS for Biomedical Engineering Students

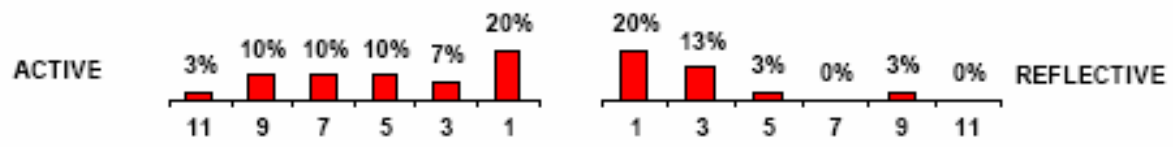

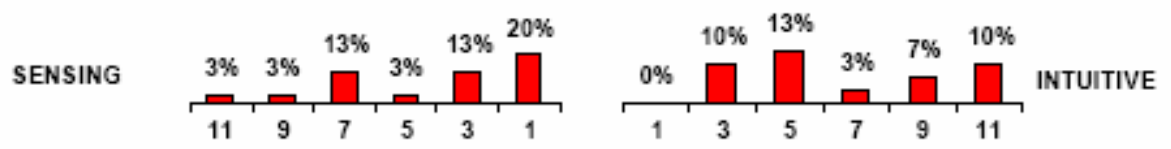

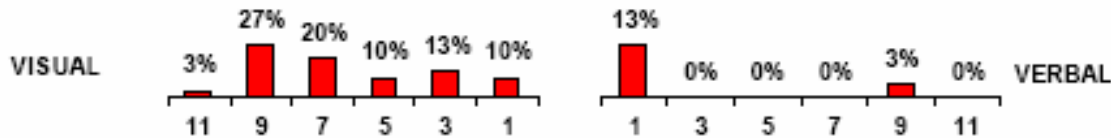

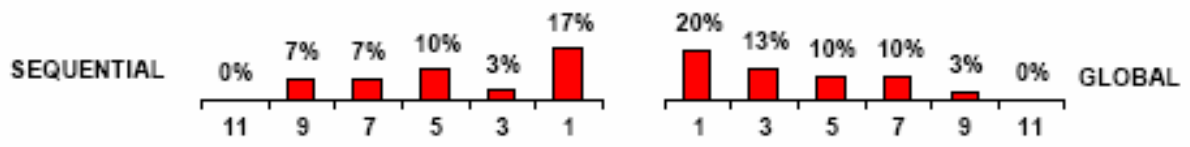




\section{Summary and discussion}

The Applied Biology and Biomedical Engineering program is relatively new to Rose-Hulman. The first freshman class of biology majors was accepted in 2001. The first freshman class of biomedical engineering majors was accepted in 2003. From 2001 to 2003, the student composition of the genetics course was predominantly biology majors. As the biomedical engineering program grew from 2003 to 2005, the number of biomedical engineering students in the genetics course began to exceed the number of "traditional" biology majors (in the 2005 genetics course, biomedical engineering students outnumbered biology students $\sim 3: 1$ ). This preliminary study evaluates the performance of biomedical engineering students enrolled in a genetics course originally designed for biology majors. This study addresses possible obstacles that may be encountered when offering a full genetics course to biomedical engineering students, such as appropriate placement of this course in the curriculum, and differences in learning styles and preferences. This study also assesses how exposure to advanced topics in genetics, including bioinformatics and recombinant DNA technology, may influence a biomedical engineering student's problem solving ability, academic interests, and career goals.

In this study, there are no statistical differences between biology and biomedical engineering students' learning preferences (according to ILS distribution). Although the sample size is too small for proper statistical analyses, this finding suggests that biomedical engineering students prefer to learn in much the same fashion as biology students, with a slight preference for visual learning.

One consideration in offering an upper-level genetics course to biomedical engineering students is proper placement of the course within the demanding engineering curriculum. At RoseHulman, biomedical engineering students take "Mendelian and Molecular Genetics" during the fall of the junior year; the previous biology course ("Evolution and Diversity") is offered during the spring of the freshman year. Despite the absence of biology courses during the sophomore year, biomedical engineering students performed equally well as sophomore biology majors, who completed the core biology sequence in the previous quarter. These results demonstrate that biomedical engineering students are highly capable of succeeding in a "mainstream" genetics course designed for biologists, even if this course is postponed to $3^{\text {rd }}$ year.

In response to the results from this survey, student evaluations, and the recent shift in course composition towards biomedical engineering students, minor revisions to the genetics course have been proposed. For example, biomedical engineering students requested that the course content specifically address and emphasize the link between genetics and their curriculum. Student presentations may provide an excellent opportunity for biomedical engineering students to explore the connection between genetics and engineering without dramatically altering the traditional core content of the course. In previous courses, students were asked to research contemporary topics in genetics (e.g. gene silencing, genomic imprinting, gene therapy) and present "mini-lectures" to the class. To strengthen the relationship between biomedical engineering and genetics - and to encourage students to discover these connections on their own-biomedical engineering students will be asked to research topics in genetics that specifically relate to their particular track: bioinstrumentation, biomaterials, or biomechanics. 
Genetic analysis can provide engineering students with a powerful toolbox to address complex biomedical questions. Most biomedical engineering students in this survey reported that a full genetics course complemented and strengthened their engineering curriculum, and provided a more comprehensive understanding of the biological side of biomedical engineering. For many engineering students, this also translated into a revived appreciation for the biological aspect of biomedical engineering, as well as an enhanced ability to approach engineering problems from a biological perspective.

\section{Bibliography}

1. $\quad$ Felder, Richard, "Reaching the Second Tier: Learning and Teaching Styles in College Science Education." J. College Science Teaching, 23(5), 286-290 (1993). 